\title{
QUALIDADE PÓS-COLHEITA DE MANGAS, NÃO-REFRIGERADAS, E SUBMETIDAS AO CONTROLE DAAÇÃO DO ETILENO ${ }^{1}$
}

\author{
LEANDRO CAMARGO NEVES², RONALDO MORENO BENEDETTE ${ }^{3}$, VANUZAXAVIER DA SILVA ${ }^{3}$, \\ MARCOS ANDRE DE SOUZAPRILL ${ }^{4}$, SÉRGIO RUFFO ROBERTO ${ }^{5}$, ROGÉRIOLOPES VIEITES $^{6}$
}

RESUMO-O presente trabalho objetivou-se na caracterização físico-química de mangas cv. Tommy Atkins e Haden, submetidas ao controle da ação do etileno, através da exposição dos frutos à ação de adsorvedores de etileno. Os frutos colhidos em estádio de fisiologicamente maturos foram embalados em filmes de polietileno de baixa densidade (PEBD) de 0,006 mm de espessura, com ou sem o sachê de adsorção de etileno, e acondicionados em embalagens de papelão (0,65 x 0,52 m), sem o controle da temperatura e da umidade relativa (30 $\pm 3{ }^{\circ} \mathrm{C}$ e $70 \pm 5 \%$ de U.R.). Os tratamentos ficaram constituídos dessa maneira: T1 - mangas cv. Tommy Atkins, com o sachê de adsorção; T2 - mangas cv. Tommy Atkins, sem o sachê de adsorção; T3 - mangas cv. Haden com o sachê de adsorção, e T4 - mangas cv Haden sem o sachê de adsorção. As análises de firmeza de polpa, sólidos solúveis (SS), acidez titulável (AT), pH, ácido ascórbico e concentração de etileno foram realizadas na instalação do experimento (dia 0), e aos 7; 14; 21; 28 e 35 dias; e aos 35 dias foi realizado um teste de preferência. Ao final do experimento, observou-se que, em ambas as cultivares, a menor concentração de etileno nas embalagens, a maior firmeza de polpa, a maior contenção no avanço e na diminuição do SS e AT, respectivamente, bem como a melhor manutenção do conteúdo de ácido ascórbico foram detectadas nos frutos acondicionados em embalagens contendo o sachê de adsorção de etileno. Não foram detectadas variações significativas nos valores de pH. No teste de preferência, houve variação significativa, onde os frutos acondicionados sob ação do adsorvedor de etileno foram preferidos por parte dos julgadores. Termos para indexação: Mangifera indica L., vida de prateleira, qualidade, conservação.

\section{POSTHARVEST QUALITY OF MANGOES, UNCOOLED, AND SUBMITTED TO THE ETHYLENE'S CONTROLACTION}

\begin{abstract}
The present work was objectified in the physic-chemical characterization of mangoes cv. Tommy Atkins and Haden, submitted to the control of ethylene action, trough the exposition of fruits of the ethylene's absorption system. The fruits harvested in the nature - green stage, had been packed in low density polyethylene films (LDPE) of 0,006 mm of thickness, with or without and ethylene's absorption system, conditioned in cardboard packing $(0,65 \times 0,52 \mathrm{~m})$, without the control of the temperature and the relative humidity ( $30 \pm 3{ }^{\circ} \mathrm{C}$ and $70 \pm 5 \%$ of R. H.). The treatments had been constituted in this way: T1 - mangoes cv. Tommy Atkins, with ethylene’s absorption system; T2 - mangoes cv. Tommy Atkins, without ethylene's absorption system; T3 - mangoes cv. Haden, with ethylene's absorption system e, T4 - mangoes cv. Haden, without ethylene's absorption system The analysis of pulp firmness, soluble solids (SS), titratable acidity (TA), pH, ascorbic acid and ethylene's concentration in the packing were made in the installation of the experiment (day 0) and to the 7, 14, 21, 28 and 35 days and, to the 35 days, it was carried out a preference test. In the end, it was observed, in both cultivars, the lesser concentration of ethylene in the packing, the biggest pulp firmness, the biggest containment in the advance and the reduction of SS and TA, respectively, as well as the best maintenance of ascorbic acid contents, had been detected in the fruits conditioned packed contending the ethylene's adsorption system. Significant variations in the values of $\mathrm{pH}$ had not been detected. Also, in the preference test, the fruits conditioned under the action of the ethylene's adsorption system had been the preferred ones on the part of the judges.
\end{abstract}

Index Terms: Mangifera indica L., shelf-life, quality, conservation.

\section{INTRODUÇÃO}

A manga é um dos mais importantes frutos tropicais, sendo muito apreciada por seu sabor, aroma e coloração característicos. O Brasil, segundo maior exportador de mangas no mundo (IBRAF, 2003), apresenta grande potencial de crescimento tanto para exportação quanto para o mercado interno. No ano de 2004, a produção brasileira de mangas foi de 1,15 milhão de toneladas, em aproximadamente 73 mil hectares, e as exportações atingiram US\$ 72,5 milhões com 113 mil toneladas de frutos (Agrianual, 2005). Mesmo diante da grande potencialidade, diversidade de tipos e de cultivares, ainda existe o contraste negativo com as condições precárias de armazenamento e comercialização desse fruto (Yanru et al., 1995).

Vale ressaltar que os mercados para as exportações são cada vez mais exigentes quanto à qualidade dos frutos. Frutos tropicais e climatéricos, como é o caso das mangas, não resistem mais do que 20 a 25 dias de transporte. Desse modo, seria

${ }^{1}$ (Trabalho 092-07). Recebido em: 10-04-2007. Aceito para publicação em: 09-11-2007.

${ }^{2}$ UFRR-Prof.Depto de Fitotecnia-Centro de Ciências Agrárias, km 12 BR174 s/nº, CEP 69301-970, Boa Vista-RR. rapelbtu@hotmail.com.

${ }^{3}$ UFRR-Graduando em Agronomia-Centro de Ciências Agrárias, km 12 BR174 s/nº, CEP 69301-970, Boa Vista-RR. rmbenedette@hotmail.com, vanuzaxavier@hotmail.com.

${ }^{4}$ UFRR-Pós-graduando em Ciência e Tecnologia de Alimentos - Centro de Ciências Agrárias, Km 12 BR174 s/nº, CEP 69301-970, Boa Vista/RR. marcosprill@bol.com.br.

${ }^{5}$ UEL-Prof.Dr.Depto. Agronomia - Centro de Ciências Agrárias, C.P.6001, CEP 86051-990, Londrina-PR. sroberto@uel.br.

${ }^{6}$ UNESP/FCA-Prof. Depto de Gestão e Tecnologia Agroindustrial, C.P. 237, CEP 18603-970, Botucatu-SP. vieites@fca.unesp.br. 
necessário desenvolver tecnologias para prolongar a vida póscolheita desses frutos, viabilizando, por sua vez, o transporte marítimo, cujo custo do frete é bem inferior ao transporte aéreo. A produção e a sensibilidade ao etileno são considerados fatores importantes quanto ao processo total de amadurecimento dos frutos. Uma das características marcantes de espécies climatéricas, como a manga, é a capacidade de exibir produção autocatalítica de etileno (Cocozza, 2003). Essa substância, produzida naturalmente, é um fitormônio atuante no amadurecimento de frutos climatéricos, acelerando desse modo a velocidade do metabolismo respiratório desses frutos (Pech et al., 1994; Chaves et al., 1997).

$\mathrm{Na}$ maioria dos frutos climatéricos, o aumento da concentração de etileno nos espaços intercelulares precede o processo de amadurecimento, bem como pode induzir ao processo autocatalítico de síntese, como já anteriormente citado (Mosca et al., 1999). Assim, no armazenamento de mangas, devem ser aplicadas embalagens ativas, principalmente com adsorvedores de etileno, que é um metabólito indesejável à manutenção da conservação do próprio fruto. A diminuição da produção e/ou atividade do etileno, em frutos, é vital para o prolongamento da vida útil desses, pois o etileno funciona como acelerador da maturação e/ou amadurecimento (Pfaffenbach et al., 2003). Nesse mesmo estudo, Pfaffenbach et al. (2003) constataram que a embalagem plástica de PEBD, de 0,025 mm de espessura, contendo um sachê de permanganato de potássio, apresentou influência significativamente positiva no controle da manutenção da qualidade de mangas espada vermelha refrigeradas. Castro et al. (2002), da mesma forma, afirmam que a embalagem PEBD, também de 0,025 mm de espessura, mais o sachê de permanganato de potássio, influenciou beneficamente na manutenção da qualidade das mangas cv. Van Dyke.

Dessa forma, a adoção de medidas que reduzam a produção e/ou a ação desse fitoregulador, pode retardar a velocidade de amadurecimento e, conseqüentemente, aumentar o tempo de conservação desses frutos (Pech et al., 1994; Chaves et al., 1997).

Nesse sentido, vislumbrando mais uma alternativa ao armazenamento refrigerado, avaliou-se a qualidade físico-química de mangas cv. Tommy Atkins e Haden, armazenadas em condições de temperatura e umidade relativa não-controladas, através do uso de adsorvedores de etileno acondicionados dentro de embalagens de PEBD.

\section{MATERIAL E MÉTODOS}

O experimento foi realizado na safra de 2005, no município de Boa Vista - RR. Os frutos foram colhidos em estádio de fisiologicamente maturos e apresentavam, no momento da colheita, coloração verde-avermelhada (cv. Haden) e verdearroxeada (cv. Tommy Atkins), sólidos solúveis (SS) médios de 8,9 ${ }^{\circ}$ Brix (cv Haden) e 9,1 ${ }^{\circ}$ Brix (cv. Tommy Atkins), acidez titulável (AT), em média, de 1,09 \% de ácido cítrico (cv. Haden) e 1,13 \% de ácido cítrico (cv. Tommy Atkins) e massa média de 675 g (cv. Haden) e 583 g (cv. Tommy Atkins).

Após a colheita, os frutos foram selecionados pela ausência de danos e/ou podridões e higienizados em solução de hipoclorito de sódio $(\mathrm{NaOCl})$ a $50 \mathrm{mgL}^{-1}$, previamente, por 10 minutos e secos ao ar livre. Em seguida, foram embalados em filmes de polietileno de baixa densidade (PEBD) de 0,006 mm e acondicionados em embalagens de papelão $(0,65 \times 0,52 \mathrm{~m}$, contendo 6 frutos/embalagem), sem o controle das condições de temperatura e umidade relativa $\left(30 \pm 3{ }^{\circ} \mathrm{C}\right.$ e $70 \pm 5 \%$ de U.R.), em galpão coberto e bem ventilado. Dentro de cada embalagem de PEBD, foram colocados sachês adsorvedores de etileno (um em cada embalagem), marca comercial Longfresh ${ }^{\circledR}$, peso unitário de nove gramas, contendo silicato de alumínio e permanganato de potássio (1:1). Os tratamentos foram assim distribuídos: T1 mangas cv. Tommy Atkins, com o sachê de adsorção; T2 - mangas cv. Tommy Atkins, sem o sachê de adsorção; T3 - mangas cv. Haden, com o sachê de adsorção; T4 - mangas cv Haden, sem o sachê de adsorção.

As análises físico-químicas e sensoriais, realizadas no Laboratório de Fitotecnia da Universidade Federal de Roraima (UFRR), na colheita (dia 0), e aos 7; 14; 21; 28 e 35 dias de armazenamento não-refrigerado $\left(30 \pm 3^{\circ} \mathrm{C}\right.$ e $70 \pm 5 \%$ de U.R.), foram quanto: à firmeza de polpa, determinada com o auxílio de penetrômetro manual, marca "Fruit pressure” test mod.FT327 (327 lbs), ponteira de 11mm de diâmetro. Os resultados foram expressos em $\mathrm{N}$ (Newtons).

Os SS foram determinados por refratometria (Carvalho, 1990), com o emprego de refratômetro, marca ATAGO, modelo $\mathrm{N} 1$. Os resultados foram expressos em ${ }^{\circ}$ Brix.

AAT foi determinada por titulometria de neutralização (Carvalho, 1990), por titulação de 10 g de polpa, homogeneizada e diluída para $100 \mathrm{~mL}$ em água ultrapura, com solução padronizada de hidróxido de sódio a 0,01 N, e ponto de viragem com $\mathrm{pH}=8,2$. Os resultados foram expressos em \% de ácido cítrico.

$\mathrm{O}$ pH foi determinado através de potenciometria em amostra triturada e homogeneizada, segundo Carvalho (1990). O teor de ácido ascórbico (mg de ácido cítrico.100 g de polpa ${ }^{-1}$ ) foi determinado segundo método de Carvalho et al. (1990), que se baseia na redução do indicador 2,6 - diclorobenzenoindolfenol (DCFI) pelo ácido ascórbico.

A concentração de etileno foi quantificada por cromatografia gasosa, utilizando um cromatógrafo a gás, marca Varian ${ }^{\circledR}$, modelo 3300, equipado com uma coluna de aço inox 1/ 8", preparado com Porapak ${ }^{\circledR}$, e um detector de ionização de chama. Para a determinação da concentração de etileno nas embalagens, foram coletadas amostras da atmosfera gasosa da embalagem de PEBD, de cada tratamento, através de seringas hipodérmicas, contendo $8 \mathrm{~mL}$ da atmosfera gasosa de cada embalagem de PEBD, sendo os resultados expressos em $\mathrm{kPa}$.

Realizou-se, ao final dos 35 dias, visando a sensorialmente avaliar o efeito na manutenção da qualidade físico-química das mangas, um teste de preferência, contando com vinte julgadores treinados, orientados para a aplicação de escala hedônica de 5 pontos (Moraes, 1988) - gostei muitíssimo (nota 5); gostei muito (nota 4); gostei (nota 3); desgostei muito (nota 2), e desgostei muitíssimo (nota 1$)$.

Realizada uma análise exploratória dos dados, constatouse que os mesmos seguem uma distribuição normal, os erros são 
independentes e apresentam homocedasticidade. Assim, os dados foram submetidos à análise de variância, pelo teste F, e a comparação de médias foi efetuada pelo teste de Tukey DMS, a $5 \%$ de probabilidade. O delineamento experimental empregado foi o inteiramente casualizado, seguindo um esquema fatorial 2x2x6 (adsorvedor de etileno, cultivares e armazenamento), com 4 tratamentos e 5 repetições.

\section{RESULTADOS E DISCUSSÃO}

De acordo com os resultados obtidos na análise de $\mathrm{pH}$ (Tabela 1), não foram encontradas diferenças significativas entre os tratamentos testados ao final do experimento. O mesmo foi observado por Pfaffenbach et al. (2003), trabalhando com mangas espada frigoarmazenadas e também submetidas ao sachê adsorvedor de etileno. No entanto, pôde-se observar, em todos os tratamentos aqui testados, mesmo que de maneira desuniforme, tendência discreta no decréscimo dos teores de $\mathrm{pH}$ ao longo do tempo. Em ambas as cultivares, ao final do período experimental, os valores de $\mathrm{pH}$ estiveram entre 3,46 e 3,48. Isso por sua vez é considerado normal, visto que, geralmente, frutos de manga apresentam pH ácido, abaixo de 4,5 (Berniz, 1984). Já para Pfaffenbach et al. (2003), os resultados foram um pouco diferentes, sendo que, além das mangas, apresentaram valores crescentes de $\mathrm{pH}$, os mesmos situavam-se entre 4,2 na colheita e 4,9 após 28 dias em refrigeração, e 4 dias em temperatura ambiente. Quanto a isso, os autores do presente trabalho ponderam no sentido de que, as mangas, nesse experimento, foram frigoarmazenadas durante todo o período experimental. Além disso, pelo valor de pH e SS observados (Pfaffenbach et al., 2003), pressupõe-se que as mesmas foram colhidas em um estádio de maturação mais avançado, o que, segundo os próprios autores, pode ter reduzido a vida de prateleira das mangas, mesmo sob condições de atmosfera refrigerada.

Rocha et al. (2001) encontraram valores de $\mathrm{pH}$ variando entre 3,23 a 4,51 para mangas Tommy Atkins nos estádios 'verde' a 'traços de verde'. O mesmo foi observado neste experimento, onde, ao final de 35 dias, os frutos da variedade Tommy Atkins apresentaram valores médios de $\mathrm{pH}$ de 3,46, e a variedade Haden, de 3,48 (Tabela 1). No entanto, a manutenção desuniforme dos valores de $\mathrm{pH}$ observados neste trabalho pode estar relacionada à perda de firmeza dos frutos, e esta, à liberação de ácidos pécticos oriundos da parede celular dos tecidos, influenciando assim, diretamente, na diminuição dos valores de pH. Coneglian et al. (1993), em experimento avaliando a aplicação exógena de etileno em frutos de manga cv. Keitt, também verificaram que não existiu diferença significativa entre frutos tratados ou não, quanto ao parâmetro pH. O mesmo foi observado neste experimento; entretanto, o presente trabalho objetivou-se na contenção, ao invés da adição de etileno exógeno.

Quanto às análises de firmeza de polpa (Figura 1), SS, AT e ácido ascórbico (Tabela 1), constatou-se então a eficiência tecnológica do sachê adsorvedor de etileno, principalmente no que concerne à desaceleração do metabolismo respiratório dos frutos. Sendo assim, os frutos embalados com o sachê adsorvedor de etileno apresentaram-se mais firmes, com doçura e acidez intermediárias, e com maiores teores de ácido ascórbico, ou seja, caracteristicamente em um estádio menos avançado de amadurecimento.

Sendo assim, na análise dos resultados da Figura 1, pôdese constatar que nas mangas acondicionadas com adsorvedor de etileno, em ambas as cultivares, a perda de firmeza de polpa foi menor no decorrer do experimento. Esse resultado, supostamente, deveu-se à ação do adsorvedor de etileno dentro de cada embalagem de PEBD, proporcionando melhor conservação da integridade da parede celular desses frutos, retardando por sua vez, o avanço do amadurecimento e da senescência. A utilização de adsorvedores de etileno, na forma de bolsas ou diretamente em câmaras frigoríficas, também mostrou eficiência na manutenção dos maiores níveis de firmeza de polpa durante o amadurecimento de mangas, segundo Castro - López et al. (2001). Brackmann et al. (2005) sugerem que frutos com alta taxa respiratória e elevada produção de etileno, como é caso das mangas trabalhadas neste experimento, apresentaram diminuição dos níveis desse gás, o que proporcionou frutos com maior firmeza de polpa e a manutenção do percentual de AT. O mesmo foi verificado neste experimento; entretanto, ao invés de se utilizarem câmaras de frigoarmazenamento com sistemas de controle atmosféricos, alternativamente, o presente trabalho utilizou, com sucesso, embalagens de PEBD de 0,006 mm contendo sachês de adsorção de etileno, que não custam mais do que R\$ 0,25 (Soloeste, 2006), alcançando resultados semelhantes. Vale ressaltar que a ação do permanganato de potássio se baseia exclusivamente na adsorção do etileno produzido pelas mangas, impedindo-o, substancialmente, de acelerar a maturação e/ou amadurecimento desses frutos.

Sobre o comportamento observado para a firmeza de polpa dos frutos, a exemplo dos resultados aqui obtidos, vários pesquisadores (Valente et al., 2000; Báez-Sañudo et al., 2001) também relataram a diminuição constante da firmeza de polpa dos frutos durante a pós-colheita. Diante disso, os autores pressupõem que todos os frutos apresentavam amadurecimento fisiologicamente característico. Entretanto, como se observou na Figura 1, todos os frutos embalados junto com sachês de adsorção de etileno apresentaram as menores perdas de firmeza de polpa. Condiciona-se esse resultado justamente à diminuição na velocidade dos processos metabólicos, proporcionando, conseqüentemente, a preservação das cadeias pécticas polimerizadas da parede celular, por maior período de tempo, influenciando, assim, na manutenção da firmeza de polpa durante o armazenamento dos frutos.

Segundo a Tabela 1, observou-se a elevação dos teores de SS em todos os tratamentos, durante o período experimental. Assim, detectaram-se diferenças significativas a partir do $14^{\circ}$ dia entre T1 e T2 (manga cv. Tommy Atkins), bem como entre T3 e T4 (manga cv. Haden), a partir do $7^{\circ}$ dia, respectivamente com e sem o adsorvedor de etileno. Isso pode ser devido à ação metabólica do adsorvedor de etileno, no que concerne à diminuição da velocidade dos processos relacionados ao amadurecimento.

Nesse sentido, os frutos submetidos à ação do adsorvedor aparentavam estar em um estádio de amadurecimento menos avançado que os demais frutos. Dessa forma, confirmou-se o 
efeito positivo da ação do adsorvedor de etileno, reduzindo a velocidade do processo natural de senescência, ou seja, contendo o rápido incremento dos teores de SS. Pfaffenbach et al. (2003) novamente apresentaram resultados distintos dos obtidos neste experimento, onde, não só no parâmetro $\mathrm{pH}$, mas também para os teores de SS e AT, não foram detectadas diferenças significativas. Entretanto, como citado anteriormente, isso pode ser advindo do avançado estádio de maturação das magas utilizadas.

Ainda, segundo Neves et al. (2004), para a maioria dos frutos colhidos em estádio pré-climatérico e armazenados sob refrigeração ou não, pode-se observar incrementos nos teores de SS, ocasionados pela conversão de moléculas insolúveis em moléculas solúveis, como, por exemplo, açúcares solúveis, pectinas, sais e ácidos orgânicos. Da mesma forma, fora observado no decorrer deste experimento o incremento nos teores de SS, independentemente da presença do sachê adsorvedor. Porém, esse incremento deu-se de forma mais lenta quando os frutos foram colocados na presença do sachê adsorvedor, conforme a Tabela 1.

Quanto ao teor de AT (Tabela 1), o parâmetro seguiu um padrão linear de declínio em todo o período experimental. Assim, como observado na análise de SS, o sachê de adsorção de etileno também foi preponderante frente à diminuição da velocidade nas perdas de AT das mangas, o que, por sua vez, novamente pressupõe-se um estádio menos avançado de amadurecimento a esses frutos. O’Hare (1995), avaliando o efeito da temperatura na qualidade e composição química de mangas Kensington, verificou que os teores de AT também diminuíram conforme o amadurecimento dos frutos, de 1,3 para até $0,3 \%$ de ácido cítrico. $100 \mathrm{mg}$ de polpa ${ }^{-1}$, em 20 dias de armazenamento a $13^{\circ} \mathrm{C}$, e de 1,2 para até $0,1 \%$, em 20 dias de armazenamento a $22^{\circ} \mathrm{C}$. Jerônimo (2000), armazenando mangas Palmer em diferentes embalagens, nas temperaturas de $13^{\circ} \mathrm{C} \mathrm{e} 24^{\circ} \mathrm{C}$, encontrou valores de 1,10 a $0,118 \%$. Todos esses trabalhos, tanto com relação aos valores quanto ao comportamento metabólico em si, comprovam os resultados obtidos neste experimento, onde os valores de AT variaram de 1,07 a $0,20 \mathrm{~g}$ de ácido cítrico. $100 \mathrm{mg} \mathrm{de} \mathrm{polpa}^{-1}$ ao final do período experimental. Contudo, as mangas acondicionadas em PEBD, contendo o sachê adsorvedor, em ambas as cultivares, apresentaram-se, ao 35 dias, com valores superiores $(0,52 \pm 0,01 \%)$ aos demais tratamentos.

Ácidos orgânicos diminuem com o amadurecimento na maioria dos frutos, entre os quais o ácido cítrico, predominante em mangas (Mitra \& Baldwin, 1997), o que pode estar relacionado com os resultados apontados na Tabela 1. Esse comportamento, segundo os próprios autores deste trabalho, decorre do consumo dos ácidos orgânicos e/ou sua conversão em açúcares no processo respiratório das mangas.

O teor de ácido ascórbico nas mangas ‘Tommy Atkins’ e 'Haden' também variou em função da utilização do sachê adsorvedor (Tabela 1). Esse resultado foi ocasionado, possivelmente, pela menor concentração de etileno no interior das embalagens (Figura 2). Essa condição, seguramente, conduziu a desaceleração dos eventos metabólicos que conduzem a senescência dos frutos, dentre os quais a diminuição dos teores de ácido ascórbico. Sendo assim, mantendo os frutos embalados com o sachê adsorvedor de etileno, proporcionouse, além da preservação do teor de ácido ascórbico (33,05 \pm 0,45g.100 g de polpa ${ }^{-1}$ ), maior perspectiva de vida de prateleira a essas mangas. Lima (1997), semelhantemente, encontrou para as mangas Tommy Atkins concentrações de vitamina $C$ variando de 47,9 a $9,3 \% .100^{-1} \mathrm{~g}$ de polpa quando armazenadas durante 28 dias sob temperatura de $12 \pm 2{ }^{\circ} \mathrm{C}$ e umidade de $88 \pm 3 \%$.

Esses resultados são considerados importantes, visto que o consumo de alimentos funcionais tem crescido vertiginosamente nos últimos anos. Nesse sentido, pode-se considerar que o ácido ascórbico, também conhecido como vitamina $\mathrm{C}$, além das suas propriedades nutracêuticas já conhecidas, pode também atuar como agente antioxidante, contribuindo positivamente na preservação da qualidade póscolheita dos frutos. Entretanto, em todos os tratamentos testados, foram observados decréscimos progressivos nos teores de ácido ascórbico. Isso também pode ser considerado normal, visto que o teor de vitamina $\mathrm{C}$ em mangas, bem como da maioria dos frutos, pode diminuir durante o armazenamento (Cocozza, 2003). Cardello \& Cardello (1998), trabalhando com mangas cv. Haden frigoarmazenadas, também observaram redução significativa no teor de ácido ascórbico durante o amadurecimento, ocasionando, segundo os autores, a conversão desse ácido em outros compostos metabólicos.

As menores concentrações de etileno detectadas no interior das embalagens de PEBD foram observadas quando acondicionadas com o sachê adsorvedor (Figura 2), sugerindo, portanto, a relação fisiológica entre a diminuição dos níveis de etileno livre e os resultados tecnológicos anteriormente discutidos. Dessa forma, a diminuição da concentração de etileno dentro dessas embalagens permitiu, não só o aumento da vida útil desses frutos, mas também a adequada manutenção dos atributos qualitativos durante o armazenamento não-refrigerado. A adição de adsorvedores de etileno em filmes de polietileno e filmes Xtend ${ }^{\circledR}$ reduziram os níveis de etileno e $\mathrm{CO}_{2}$, melhorando a qualidade de mangas (Rosa et al., 2001). Isso corrobora diretamente a afirmação dos resultados encontrados neste trabalho. Também, Neves et al. (2006), trabalhando com caquis cv. Fuyu, observaram que a concentração de etileno nas embalagens de PEBD, contendo o sachê adsorvedor, mantevese menor do que nas embalagens sem o sistema de adsorção de etileno, demonstrando, assim, a eficiência do sachê na adsorção desse gás.

Cocozza (2003) menciona, em seus estudos, que os testes sensoriais que utilizam os órgãos dos sentidos humanos como 'instrumentos', devem ser incluídos como garantia de qualidade, por ser uma medida multidimensional integrada, capaz de determinar a aceitação de um produto por parte dos consumidores. Dessa forma, com o uso do sistema de adsorção de etileno, constatou-se, na prática, o efeito positivo nos teores de SS (Tabela 2), na manutenção da AT e dos teores de vitamina C (Tabela 3) e dos maiores valores de firmeza de polpa (Figura 1). Todos esses resultados, analisados agora conjuntamente no painel sensorial, comprovaram assim a eficiência do sachê adsorvedor na manutenção da qualidade e prolongamento de vida pós-colheita das mangas cv Tommy Atkins e Haden (Figura 3). 
Houve diferença significativa comparando-se as mangas com e sem o sistema de adsorção de etileno. Como se pôde observar na Figura 3, as mangas Tommy Atkins embaladas com sistema de adsorção apresentaram nota média 5, enquanto para a mesma cultivar sem o tratamento do adsorvedor os frutos apresentaram nota média 2. O mesmo ocorreu com a cv. Haden.

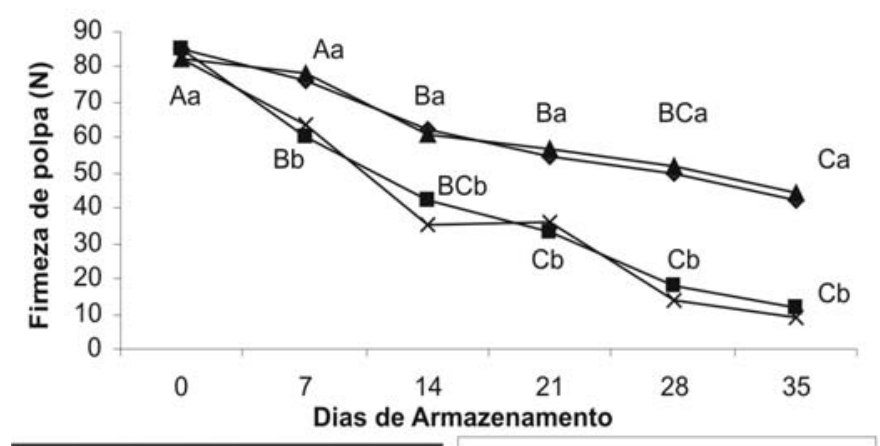

C.V. média da interação $=3,46 \rightarrow-\mathrm{T} 1 \rightarrow-\mathrm{T} 2 \rightarrow \mathrm{T} 3 \rightarrow$ T4
Possivelmente, a rejeição dos julgadores aos frutos dos tratamentos não-submetidos ao sachê de adsorção de etileno deveu-se ao avançado estádio de amadurecimento desses frutos, decorridos 35 dias de armazenamento, que pode ter modificado suas características sensoriais.

T1: mangas cv. Tommy Atkins, com o sachê de adsorção; T2: mangas cv. Tommy Atkins, sem o sachê de adsorção; T3: mangas cv. Haden, com o sachê de adsorção; T4: mangas cv Haden, sem o sachê de adsorção.

As médias seguidas das mesmas letras minúscula (coluna - tratamentos) e maiúscula (lina - tempo) não diferem entre si, ao nível de 5\% de probabilidade, pelo teste de Tukey.

FIGURA 1 - Firmeza de polpa, em mangas cv. Tommy Atkins e Haden, submetidas ou não ao sistema de adsorção de etileno, e armazenadas por 35 dias, a $30 \pm 3{ }^{\circ} \mathrm{C}$ e $70 \pm 5 \%$ de U.R. Boa Vista-RR - 2005.

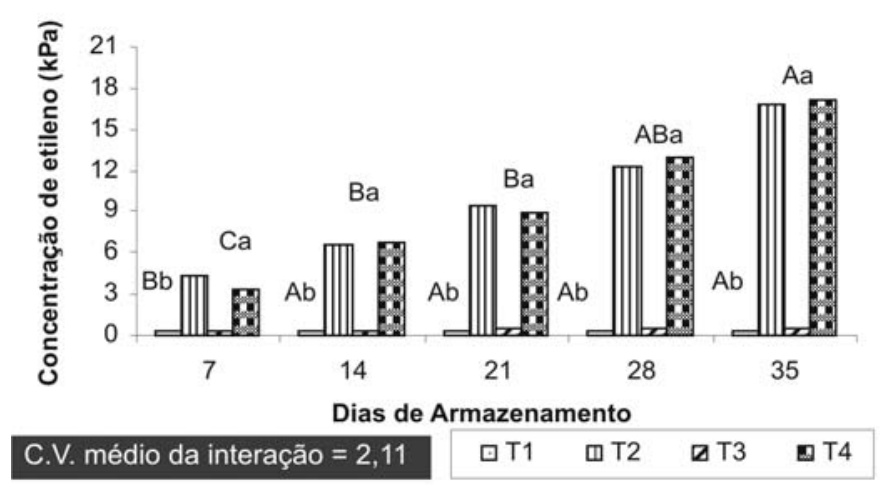

T1: mangas cv. Tommy Atkins, com o sachê de adsorção; T2: mangas cv. Tommy Atkins, sem o sachê de adsorção; T3: mangas cv. Haden , com o sachê de adsorção; T4: mangas cv Haden, sem o sachê de adsorção.

As médias seguidas das mesmas letras minúscula (coluna - tratamentos) e maiúscula (lina - tempo) não diferem entre si, ao nível de 5\% de probabilidade , pelo teste de Tukey.

FIGURA 2 - Concentração de etileno nas embalagens de PEBD, em mangas cv. Tommy Atkins e Haden, submetidas ou não ao sistema de adsorção de etileno, e armazenadas por 35 dias, a $30 \pm 3{ }^{\circ} \mathrm{C}$ e $70 \pm 5 \%$ de U.R. Boa Vista-RR - 2005.

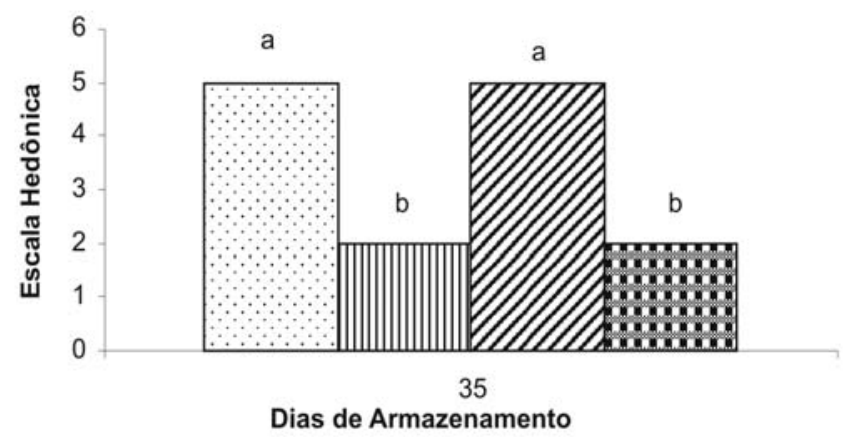

T1: mangas cv. Tommy Atkins, com o sachê de adsorção; T2:
mangas cv. Tommy Atkins, sem o sachê de adsorção; T3: mangas
cv. Haden, com o sachê de adsorção; T4: mangas cv Haden,
sem o sachê de adsorção.

Dias de Armazenamento

C.V. médio da interação $=0,93 \quad \square T 1 \quad \square T 2 \quad \square T 3 \quad \square T 4$

As médias seguidas das mesmas letras, não diferem entre si ao nível de 5\% de probabilidade pelo teste de Tukey.

FIGURA 3 - Teste de preferência (1 - desgostei muitíssimo a 5 - gostei muitíssimo), em mangas cv. Tommy Atkins e Haden, submetidas ou não ao sistema de adsorção etileno, e armazenadas por 35 dias, a $30 \pm 3^{\circ} \mathrm{C}$ e $70 \pm 5 \%$ de U.R. Boa VistaRR-2005. 
TABELA 1 - pH; sólidos solúveis; acidez titulável e ácido ascórbico, em mangas cv. Tommy Atkins e Haden, submetidas ao controle da ação do etileno e armazenadas por 35 dias, a $30 \pm 3{ }^{\circ} \mathrm{C} \mathrm{e} 70 \pm 5 \%$ de U.R. Boa Vista-RR - 2005.

\begin{tabular}{|c|c|c|c|c|c|c|c|}
\hline \multirow[t]{2}{*}{ Variáveis } & \multirow[t]{2}{*}{ Tratamentos } & \multicolumn{6}{|c|}{ Tempo (dias) } \\
\hline & & 0 & 7 & 14 & 21 & 28 & 35 \\
\hline \multirow{6}{*}{$\mathrm{pH}$} & $\mathrm{T} 1$ & $3,45 \mathrm{Aa}$ & $3,47 \mathrm{Aa}$ & $3,48 \mathrm{Aa}$ & $3,56 \mathrm{Aa}$ & $3,46 \mathrm{Ab}$ & $3,47 \mathrm{Aa}$ \\
\hline & $\mathrm{T} 2$ & $3,45 \mathrm{Aa}$ & $3,48 \mathrm{Aa}$ & $3,40 \mathrm{Bb}$ & $3,44 \mathrm{Bb}$ & $3,51 \mathrm{Aa}$ & $3,46 \mathrm{Aa}$ \\
\hline & $\mathrm{T} 3$ & $3,49 \mathrm{Aa}$ & $3,46 \mathrm{Aa}$ & $3,47 \mathrm{Aa}$ & $3,46 \mathrm{Ab}$ & $3,46 \mathrm{Ab}$ & $3,48 \mathrm{Aa}$ \\
\hline & $\mathrm{T} 4$ & $3,49 \mathrm{Aa}$ & $3,45 \mathrm{Aa}$ & $3,41 \mathrm{Bb}$ & $3,44 \mathrm{ABb}$ & $3,38 \mathrm{Cc}$ & $3,48 \mathrm{Aa}$ \\
\hline & \multicolumn{7}{|c|}{ C.V. da interaçãa $=1,72$} \\
\hline & & 0 & 7 & 14 & 21 & 28 & 35 \\
\hline \multirow{6}{*}{$\begin{array}{l}\text { Sólidos Solúveis } \\
\text { ( }{ }^{\circ} \text { Brix) }\end{array}$} & $\mathrm{T} 1$ & $9,1 \mathrm{Ba}$ & $9,5 \mathrm{Bab}$ & $11,2 \mathrm{ABb}$ & $12,1 \mathrm{Ab}$ & $13 \mathrm{Ab}$ & $13,3 \mathrm{Ab}$ \\
\hline & $\mathrm{T} 2$ & $9,1 \mathrm{Ba}$ & $9,9 \mathrm{Ba}$ & $12,3 \mathrm{Aa}$ & $13,5 \mathrm{Aa}$ & $13,9 \mathrm{Aa}$ & $14,4 \mathrm{Aa}$ \\
\hline & $\mathrm{T} 3$ & $8,9 \mathrm{Ba}$ & $9,3 \mathrm{Bb}$ & $11,4 \mathrm{Ab}$ & $11,8 \mathrm{Ab}$ & $12,9 \mathrm{Ab}$ & $13,5 \mathrm{Ab}$ \\
\hline & $\mathrm{T} 4$ & $8,9 \mathrm{Ba}$ & $9,8 \mathrm{Ba}$ & $12 \mathrm{Aa}$ & $13,2 \mathrm{Aa}$ & $14 \mathrm{Aa}$ & $14,5 \mathrm{Aa}$ \\
\hline & \multicolumn{7}{|c|}{ C.V. da interaçãa $=2,61$} \\
\hline & & 0 & 7 & 14 & 21 & 28 & 35 \\
\hline \multirow{6}{*}{$\begin{array}{l}\text { Acidez Titulável } \\
\text { (\% de ácido cítrico) }\end{array}$} & $\mathrm{T} 1$ & $1,13 \mathrm{Aa}$ & $0,98 \mathrm{Aa}$ & $0,81 \mathrm{ABa}$ & $0,76 \mathrm{Ba}$ & $0,61 \mathrm{Ba}$ & $0,53 \mathrm{Ba}$ \\
\hline & $\mathrm{T} 2$ & 1,13Aa & $0,92 \mathrm{Aab}$ & $0,62 \mathrm{Bb}$ & $0,39 \mathrm{Bb}$ & $0,29 \mathrm{BCb}$ & $0,20 \mathrm{Cb}$ \\
\hline & $\mathrm{T} 3$ & $1,09 \mathrm{Aa}$ & $0,96 \mathrm{Ab}$ & $0,78 \mathrm{Bab}$ & $0,69 \mathrm{Ba}$ & $0,63 \mathrm{Ba}$ & $0,51 \mathrm{Ba}$ \\
\hline & $\mathrm{T} 4$ & $1,09 \mathrm{Aa}$ & $0,90 \mathrm{Ab}$ & $0,65 \mathrm{Bb}$ & $0,42 \mathrm{Bb}$ & $0,32 \mathrm{BCb}$ & $0,22 \mathrm{Cb}$ \\
\hline & \multicolumn{7}{|c|}{ C.V. da interaçãa $=2,54$} \\
\hline & & 0 & 7 & 14 & 21 & 28 & 35 \\
\hline \multirow{4}{*}{$\begin{array}{l}\text { Ácido Ascórbico } \\
\left.\text { (mg.100 g de polpa }{ }^{-1}\right)\end{array}$} & $\mathrm{T} 1$ & $56,8 \mathrm{Aa}$ & $49,8 \mathrm{Aa}$ & $44,5 \mathrm{ABa}$ & $39,7 \mathrm{Ba}$ & $37,5 \mathrm{Ba}$ & $32,6 \mathrm{Ba}$ \\
\hline & $\mathrm{T} 2$ & $56,8 \mathrm{Aa}$ & $40,1 \mathrm{Bb}$ & $33,2 \mathrm{Bb}$ & $21,4 \mathrm{Cb}$ & $16,2 \mathrm{Cb}$ & $12,3 \mathrm{Cb}$ \\
\hline & $\mathrm{T} 3$ & $54,3 \mathrm{Ab}$ & $39,8 \mathrm{Bb}$ & $42,1 \mathrm{ABa}$ & $38,3 \mathrm{Ba}$ & $35,4 \mathrm{Ba}$ & $33,5 \mathrm{Ba}$ \\
\hline & $\mathrm{T} 4$ & $54,3 \mathrm{Ab}$ & $37,4 \mathrm{Bb}$ & $30,9 \mathrm{BCb}$ & $20,9 \mathrm{Cb}$ & $15,9 \mathrm{Cb}$ & $6,4 \mathrm{Dc}$ \\
\hline
\end{tabular}

As médias seguidas das mesmas letras minúscula (coluna - tratamentos) e maiúscula (lina - tempo) não diferem entre si, ao nível de 5\% de probabilidade, pelo teste de Tukey.

* T1: mangas cv. Tommy Atkins, com o sachê de adsorção; T2: mangas cv. Tommy Atkins, sem o sachê de adsorção; T3: mangas cv. Haden, com o sachê de adsorção; T4: mangas cv Haden ,sem o sachê de adsorção.

\section{CONCLUSÕES}

1-A diminuição da concentração de etileno livre no interior das embalagens teve influência direta na manutenção das características qualitativas das mangas cv. Tommy Atkins e Haden. Os resultados do trabalho relacionam a menor concentração de etileno nas embalagens, à melhor qualidade final dos frutos submetidos ao sachê de adsorção de etileno, durante os 35 dias, nas condições aqui estabelecidas de temperatura e umidade relativa.

2-Contudo, sempre que possível, deve-se fazer o uso do sachê de permanganato de potássio/silicato de alumínio e da embalagem de PEBD, com 0,006 mm de espessura, juntamente com o armazenamento refrigerado, melhorando ainda mais a conservabilidade desses frutos. Os resultados aqui apresentados apenas propõem mais uma alternativa à conservação de mangas, principalmente em regiões onde a refrigeração possa tornar-se um fator limitante.

\section{REFERÊNCIAS}

AGRIANUAL 2006: Anuário da agricultura brasileira. Manga: um novo destino. FNP Consultoria \& Comércio, 2005. p.66-69. BÁEZ-SAÑUDO, R.; BRINGAS, T.E.; GONZÁLES,A.G.; OJEDA, C.J.; MENDOZA, W.A.; RAMOS, C.G. Evaluación de películas comestibles sobre la vida postcosecha del mango. Proceedings of the Interamerican Society Tropical Horticultural, Miami, v.41, p.172-178, 2001.

BERNIZ, P.J. Avaliação industrial de variedades de manga (Mangifera indica L.) para elaboração de nectar. 1984. 55f. Dissertação (Mestrado em Fisiologia Vegetal) - Universidade Federal de Viçosa, Viçosa, 1984.

BRACKMANN, A.; GIEHL, R.F.H; PINTO, J.A.V.; STEFFENS, C.A.; SESTARI, I. Qualidade de maçãs 'Gala' armazenadas em atmosfera controlada dinâmica e estática com renovação do ar. Ciência Rural, Santa Maria, v.35, n.2, p.465-467, 2005.

CARDELLO, H. M..; CARDELLO, L. Teor de vitamina C, atividade de ascorbato oxidase e perfil sensorial de manga (Mangifera indica L.) var. Haden, durante o amadurecimento. Revista Ciência e Tecnologia de Alimentos, Campinas, v.18., n. 2, p.211-217, 1998.

CARVALHO, C. R. L.; MANTOVANI, D. M. B.; CARVALHO, P. R. N.; MORAES, R. M. M. Análises químicas de alimentos: manual técnico. Campinas: Instituto de Tecnologia de Alimentos, 1990.121p.

CASTRO, J.V.; PFAFFENBACH, L.B.; CARVALHO, C.R.L.; ROSSETTO, C.J. Efeito da atmosfera modificada e da refrigeração na conservação pós-colheita de mangas Van Dyke. In: REUNIÃO ANUAL DO INSTITUTO BIOLÓGICO, 15., 2002, Campinas, Resumos... v.69. suplemento.

CASTRO-LÓPEZ, T., Manejo de La Maduración Post-cosecha en Mango y Papaya. Revista Ibero-Americana de Tecnologia Postcosecha, Hermosillo, v.4, n.1, p.46-54, 2001.

CHAVES, A L.; ZIMMER, P. D.; SILVA, J. A; ROMBALDI, C. V. Caracterização Imunoquímica da ACC oxidase em frutas climatéricas. Revista Brasileira de Ciência e Tecnologia de Alimentos, Campinas, n. 17, p. 320-324, 1997.

COCOZZA, F. del M. Maturação e conservação de manga “Tommy Atkins” submetida à aplicação pós-colheita de 1 metilciclopropeno. 2003. 226 f. Tese (Doutorado Engenheria Agrícola) - Faculdade de Engenharia Agrícola, Universidade Estadual de Campinas, Campinas - SP, 2003. 
CONEGLIAN, R.C.C.; RODRIGUES, J.D.; BRASIL, O.G. Efeito da aplicação de etileno no $\mathrm{pH}$, acidez, índice refratométrico e açúcares totais de frutos de manga, colhidos em estágio préclimatérico. Scientia Agricola., Piracicaba, v. 50, n. 2, p.185-192, 1993.

IBRAF - INSTITUTO BRASILEIRO DE FRUTAS. Mercanotas. Informativo IBRAF, São Paulo, n.18, 2003.

JERÔNIMO, E. M. Efeito do uso de embalagens associadas a armazenamento sob refrigeração, na conservação pós-colheita de mangas ‘Tommy Atkins'e ‘Palmer’. 2000. 121f. Dissertação (Mestrado) - Faculdade de Ciências Agronômicas e Veterinárias de Jaboticabal, Universidade Federal Paulista, Jaboticabal, 2000.

LIMA, L. C. de O. Tecido esponjoso em manga 'tommy atkins': transformações químicas e bioquímicas no mesocarpo durante o armazenamento. 1997. 151f. Tese (Doutorado Ciência dos Alimentos), Universidade Federal de Lavras, Lavras, 1997.

MITRA, S.K.; BALDWIN, E. A. Mango In: MITRA, S.K. Postharvest physiology and storage of tropical and subtropical fruits. New York: CAB International, 1997. p.85-122.

MORAES, M.A.C. Métodos para avaliação sensorial dos alimentos. 6.ed. Campinas: Editora Unicamp, 1988.

MOSCA, J. L.; MUGNOL, M. M.; VIEITES, R. L. Atmosfera modificada na pós-colheita de frutas e hortaliças. Botucatu: FEPAF, 1999. 28p.

NEVES, L. C.; BENEDETTE, R. M.; SILVA., V. X.; LUCHETTA., L.; ZANUZZO., M. R.; ROMBALDI., C. V.; Comportamento pós - colheita de caquis cv. Fuyu, através da atmosfera modificada passiva e da adsorção de etileno armazenados sob refrigeração. Revista Brasileira de Fruticultura, Jaboticabal, v. 28, n. 3, p.431434, 2006.

NEVES, L. C.; LUCCHETTA., L.; MARINI.; L.; ZANUZZO., M.; ZANATTA., J.; ROMBALDI., C. V.; Armazenamento refrigerado de caquis 'Fuyu', sob atmosfera modificada com adsorção de etileno. Revista Brasileira de Fruticultura, Jaboticabal, v. 26, n. 3, p.414-418, 2004.
O'HARE, T. J. Effect of ripening temperature on quality and compositional changes of mango (Mangifera indica L.) cV. Kensington. Australian Journal of Experimental Agricultural, Victoria, v.35, n.2, p.259-63, 1995.

PECH, J.C.; LATCHÉ, A.; BALAGUÉ, C.; BOUZAYEN, M.; LELIEVRE, J.M. Postharvest physiology of climacteric fruits: recent development in the biosynthesis and action of ethylene. Sciences des Aliments, Toulouse, v.14, p.3-14, 1994.

PFAFFENBACH, L.B.; CASTRO, J.V. DE; CARVALHO, C.R.L.; CARLOS JORGE ROSSETTO, C.J. The effect of modified atmosphere and refrigeration on post-harvest of mango red espada. Revista Brasileira de Fruticultura, Jaboticabal, v. 25, n. 3, p.410-413, 2003.

ROCHA, R. H. C.; MENEZES, J. B.; MORAIS, E. A.; SILVA, G. G.; AMBRÓSIO, M. M. Q.; ALVES, M. Z. Uso do índice de degradação de amido na determinação da maturidade da manga 'Tommy Atkins'. Revista Brasileira de Fruticultura, Jaboticabal, v. 23, n. 2, p.302-305, 2001.

ROSA, H.J.D.; SINGH, Z.; TAN, S.C. Effect of modified atmosphere packaging on mango ripening. Acta Horticulturae, Wageningen, v.553, p.607-609, 2001.

SOLOESTE. Soloeste ind. com. Exportação produtos always fresh. Disponível em: <http://soloeste.com/br/prod_etileno.htm>. Acesso em: 07 out 2006.

VALENTE M., BANZOUZI J.T., PIETRI E., DORNIER M. Évaluation non destructive de la fermeté de la mangue par la technique acoustique impulsionnelle. Fruits, Paris, v. 55, n.5, p.333-345, 2000.

YANRU, Z., PANDEY,M., PRASAD, N.K., SRIVASTAVA, G.C. Ripening associated changes in enzymes and respiratory activities in three varieties of mango (Mangifera indica L.). Indian Journal Plant Physiology, New Delhi, v. 38, n.1, p.73-6, 1995. 